\title{
Avaliação da produção de alcatrão no syngas produzido a partir de biomassa em gaseificador piloto co-corrente com vista a seu uso em motor a explosão
}

\section{Assessment of tar production in syngas produced from biomass in a pilot cocorrent gasifier aiming its use in an internal combustion engine}

\author{
Adriano Quadros ${ }^{1 \star}$ Fernando Fernandes ${ }^{2}$
}

\begin{abstract}
Resumo
Este trabalho analisa a produção de alcatrão produzido no gás de síntese proveniente de um gaseificador visando seu uso em um motor a explosão. O gaseificador utilizado no trabalho é do tipo co-corrente de duplo estágio e o motor utilizado faz parte de grupo gerador e é um motor de combustão interna MWM adaptado a ciclo Otto acoplado a um gerador síncrono trifásico de eletricidade com capacidade de 50 kVa. O gás produzido tem a composição de $16,9 \%$ de $\mathrm{H} 2$, menos do que $0,1 \%$ de $\mathrm{O} 2,50,6 \%$ de $\mathrm{N} 2$, $19,8 \%$ de CO, 10,6\% de CO2 e 2,1\% de CH4. A biomassa utilizada foi lenha de eucalipto. Após 46 horas de funcionamento o motor a explosão foi aberto para avaliação de seu estado. O motor se manteve em condições ideais de operação após 46 horas de funcionamento com o gás de síntese, não apresentando contaminação por alcatrão ou material particulado. A quantidade de HPAs no gás produzido foi de 1,30 $\mu \mathrm{g} / \mathrm{Nm}^{3}$ e de material particulado foi de $0,16 \mathrm{mg} / \mathrm{Nm}^{3}$.
\end{abstract}

Palavras-chave: : Gaseificação. Alcatrão. Biomassa

\begin{abstract}
This paper analyzes the production of tar produced in the syngas from a gasifier aiming its use in a combustion engine. The gasifier used at work is of co-current type with dual-stage and the engine used is part of a generator group and is an MWM internal combustion engine adapted to Otto cycle coupled to a triphasic synchronous generator of electricity with capacity of $50 \mathrm{kVA}$. The gas produced has a composition of $16.9 \% \mathrm{H} 2$, less than $0.1 \% \mathrm{O} 2,50.6 \% \mathrm{~N} 2,19.8 \% \mathrm{CO}, 10.6 \% \mathrm{CO} 2$ and $2.1 \%$ of CH 4 . The biomass used was eucalyptus wood. After 46 hours of operation the engine was open for assessing its state. The engine remained in ideal operating conditions after 46 hours of operation with the synthesis gas, showing no contamination by tar or particulate matter. The amount of PAHs in the gas produced was $1.30 \mathrm{~g} / \mathrm{Nm}^{3}$ and particulate matter was $0.16 \mathrm{mg} / \mathrm{Nm}^{3}$
\end{abstract}

Keywords: Gasification. Tar. Biomass.

\footnotetext{
${ }^{1}$ Universidade Estadual de Londrina, Rod. Celso Garcia Cid, PR-445, km 380, Londrina, Paraná, Brasil. E-mail: adrianoquadros@ hotmail.com

${ }^{2}$ Departamento de Engenharia Civil, Universidade Estadual de Londrina, Londrina, Paraná, Brasil. E-mail: fernando@uel.br
} 


\section{Introdução}

O elevado custo da energia obtida a partir de combustíveis fósseis, aliado aos riscos ambientais que este tipo de energia apresenta, colocou em evidência as fontes de energia não convencionais, como a energia proveniente de biomassa.

A Conversão de biomassa em energia pode ser realizada através de diferentes processos, tais como os termo-químicos, bioquímico/biológico e extração mecânica. Fatores como o tipo, a quantidade de biomassa disponível, o uso final da energia produzida, padrões ambientais e condições economicas influenciam na escolha (MCKENDRY, 2002a). Dentre os processos que envolvem a conversão térmica a gaseificação possuí a melhor eficiência.

A gaseificação de biomassa é um processo termoquímico que usa a oxidação parcial para converter matérias primas orgânicas carbonáceas em um produto gasoso combustível conhecido como gás de síntese. O gás proveniente da gaseificação é composto principalmente de hidrogênio e monóxido de carbono, com menores quantidades de dióxido de carbono, água, metano, hidrocarbonetos e nitrogênio. Neste trabalho, a nomeclatura gás de síntese foi adotada para o gás proveniente da gaseificação contendo nitrogênio. As reações ocorrem em um meio de gaseificação, tal como ar, oxigênio, vapor d'água ou uma mistura desses gases a elevadas temperaturas, entre $500-1400^{\circ} \mathrm{C}$, e pressão atmosférica ou até 3-5 Mpa (FRIENDS Of THE EARTH - FOE, 2009). Durante a gaseificação as principais reações que ocorrem são de oxidação (exotérmicas) e de redução (endotérmicas), e envolvem as fases sólida e gasosa (FRANCO et al., 2003; SÁNCHEZ, 2009). As reações ocorrem simultâneamente e são as descritas na Tabela 1:
Tabela 1 - Principais reações que ocorrem no processo de gaseificação

\begin{tabular}{l|l}
\hline Reações Heterogêneas (gás-sólido) & $\begin{array}{l}\Delta \mathrm{H} \quad(\mathrm{kJ} / \\
\mathrm{mol})\end{array}$ \\
\hline Oxidação do carbono: & -111 \\
\hline $\mathrm{C}+1 / 2 \mathrm{O}_{2} \rightleftharpoons \mathrm{CO}$ & 394 \\
\hline $\mathrm{C}+\mathrm{O}_{2} \rightleftharpoons \mathrm{CO}_{2}$ & \\
\hline Reação de Boudoard: & 172 \\
\hline $\mathrm{C}+\mathrm{CO}_{2} \rightleftharpoons 2 \mathrm{CO}$ & \\
\hline Reação gás-d'água: & 131 \\
\hline $\mathrm{C}+\mathrm{H}_{2} \mathrm{O} \rightleftharpoons \mathrm{CO}+\mathrm{H}_{2}$ & \\
\hline Formação de metano: & -75 \\
\hline $\mathrm{C}+2 \mathrm{H}_{2} \rightleftharpoons \mathrm{CH}$ & \\
\hline Reações homogêneas (fase gasosa) & -41 \\
\hline $\mathrm{CO}+\mathrm{H}_{2} 0 \rightleftharpoons \mathrm{CO}+\mathrm{H}_{2}$ & 202 \\
\hline $\mathrm{CH}_{4}+\mathrm{H}_{2} \mathrm{O} \rightleftharpoons \mathrm{CO}+3 \mathrm{H}$ & \\
\hline $\mathrm{Craqueamento} \mathrm{do} \mathrm{alcatrão}_{2}$ & \\
\hline $\begin{array}{l}\mathrm{Alcatrão}+\text { Vapor }+\mathrm{Calor} \rightarrow \mathrm{CO}+ \\
\mathrm{CO}_{2}+\mathrm{CH}_{4}+\text { etc. }\end{array}$ & \\
\hline
\end{tabular}

Fonte: Franco et al. 2003; Sánchez, 2009

Todas as reações ocorrem em equilíbrio e o gás produzido consiste de uma mistura de monóxido de carbono, dióxido de carbono, metano, hidrogênio e vapor d'água.

Antes de ser gaseificada a biomassa utilizada deve ser pré-condicionada para que sua umidade esteja entre $10-30 \%$ e seu tamanho entre $0,10-200 \mathrm{~mm}$, dependendo do tipo de gaseificador.

Comercialmente, os gaseificadores disponíveis para gaseificação de biomassa são de dois tipos: leito fixo e leito fluidizado.

Os gaseificadores de leito fixo operam com temperaturas na faixa de $1000^{\circ} \mathrm{C}$ e são sub-classificados como contra-corrente e co-corrente, baseado no contato com o combustível e o agente gaseificador, como ar, oxigênio ou vapor (MCKENDRY, 2002b; QUAAK; KNOEF; STASSEN, 1999).

Um gaseificador contra-corrente (Figura 1) consiste de um leito fixo de combustível pelo qual o agente gaseificador é insuflado em direção contrária ao sentido do movimento do combustível. O combustível se move, 
por gravidade, através de diferentes zonas para secagem, pirólise, redução e oxidação. Ao passar pela zona de secagem, a biomassa é decomposta em gases voláteis e na zona de pirólise, em carvão. Na zona de redução diversas reações ocorrem, o carbono reage com vapor d'água para produzir monóxido de carbono e hidrogênio. Na zona de oxidação, o carvão é queimado para produzir calor, dióxido de carbono e vapor d'água para as reações que ocorrem na zona de redução (MCKENDRY, 2002b; QUAAK; KNOEF; STASSEN, 1999).

Figura 1 - Esquema de um gaseificador contracorrente

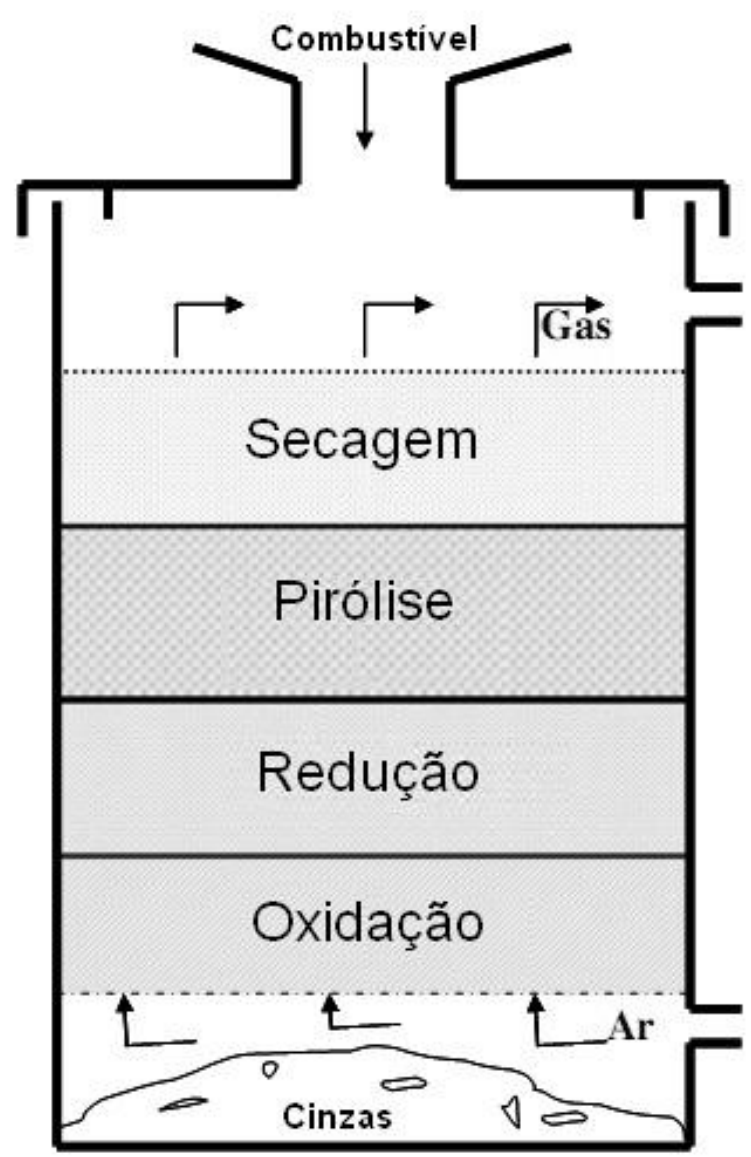

Fonte: Ciferno e Marano, 2002.

Os gaseificadores co-correntes (Figura 2) são semelhantes aos contra-correntes exceto pelo fato de o agente gaseificador fluir no mesmo sentido do combustível. Estes têm zonas similares aos contra- correntes, porém em uma ordem diferente. Calor é adicionado na parte de cima do gaseificados a partir de uma fonte de calor externa ou da combustão de pequenas quantidades de combustível. $O$ gás deixa o gaseificador a alta temperatura e o calor é transferido ao agente gaseificador, o que resulta numa eficiência energética igual à do gaseificador contra-corrente (MCKENDRY, 2002b; QUAAK; KNOEF; STASSEN, 1999).

Figura 2 - Esquema de um gaseificador cocorrente

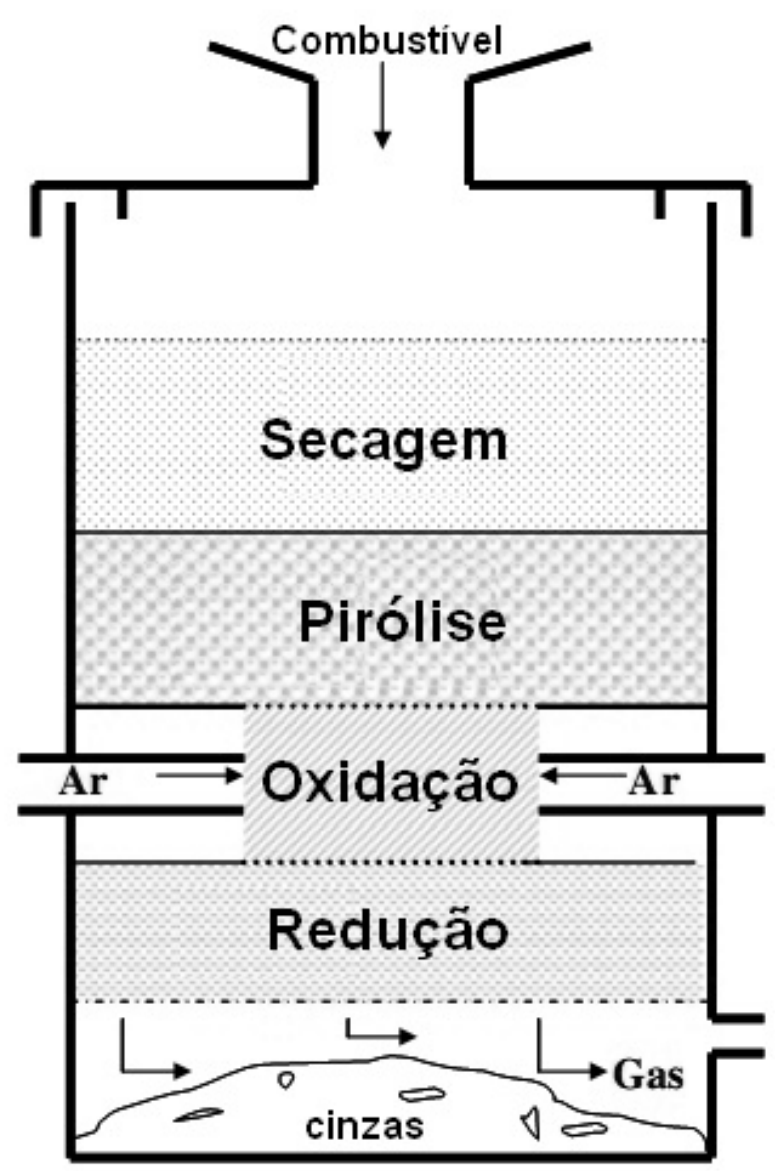

Fonte: Ciferno e Marano, 2002.

A principal vantagem do gaseificador co-corrente é a produção de um gás com pouco alcatrão, já que todo o alcatrão passa pelo leito quente de carvão onde ocorrem as reações de destruição de alcatrão. 
Entre as desvantagens estão a baixa eficiência geral, dificuldades em lidar com altas umidades e cinzas e ser adequado apenas em unidades de pequeno porte.

Um dos maiores problemas da aplicação do gás de síntese em motores é o alcatrão formado durante o processo. O alcatrão é uma mistura complexa de hidrocarbonetos condensáveis, que inclui desde compostos com 1 anel aromático em suas estruturas até compostos com 5 anéis aromáticos em suas estruturas além de outros hidrocarbonetos contendo oxigênio e hidrocarbonetos policíclicos aromáticos complexos (HPAs) (DEVI; PTASINSKI; JANSSEN, 2003).

Vários grupos de pesquisa definiram o alcatrão diferentemente. Em uma reunião sobre o protocolo de medidas de alcatrão, realizada em Bruxelas em 1998, foi acordado por um número de especialistas em definir alcatrão como todos os contaminantes orgânicos com peso molecular maior que o do benzeno. (NEEFT; KNOEF; ONAJI, 1999).

O alcatrão é indesejável devido a diversos problemas associados a sua condensação, formação de aerossóis de alcatrão e polimerização que forma estruturas mais complexas que causam problemas no equipamento e também em turbinas e motores onde o gás produzido é utilizado. (BUI; LOOF; BHATTACHARYA, 1994)

A quantidade máxima aceitável de alcatrão no gás é dependente do tipo de processo e da aplicação. Milne e Evans (1998) reportaram limites de tolerância de alcatrão para diversos usos finais: $\quad 50-500 \mathrm{mg} / \mathrm{Nm}^{3}$ (compressores), $\quad 50-100$ $\mathrm{mg} / \mathrm{Nm}^{3}$ (sistemas de combustão interna) e $5 \mathrm{mg} /$ $\mathrm{Nm}^{3}$ (turbinas à gás industriais).

Devido à produção de um gás com pouco alcatrão, gaseificadores co-corrente são os mais indicados na produção de gases para alimentação de motores de combustão interna e consequente produção de energia através de grupos-geradores.

O objetivo deste trabalho é analisar a quantidade de alcatrão e materiais particulados no syngas produzido e avaliar as condições do grupo gerador após 46 horas de funcionamento utilizando-se o syngas.

\section{Materiais e Métodos}

O trabalho desenvolvido consiste na análise da produção de alcatrão em um sistema autônomo de geração de energia elétrica a partir de biomassa. Sendo assim na sequencia do presente item são apresentados em detalhes cada um dos itens utilizados.

\section{Gaseificador}

Para o desenvolvimento deste trabalho foi utilizado um gaseificador co-corrente de duplo estágio. Na Figura 3 é representado um esquema do gaseificador utilizado. Os equipamentos de medição tem precisão industrial e não foi realizado um tratamento dos erros e incertezas.

Figura 3 - Representação esquemática do gaseificador utilizado.

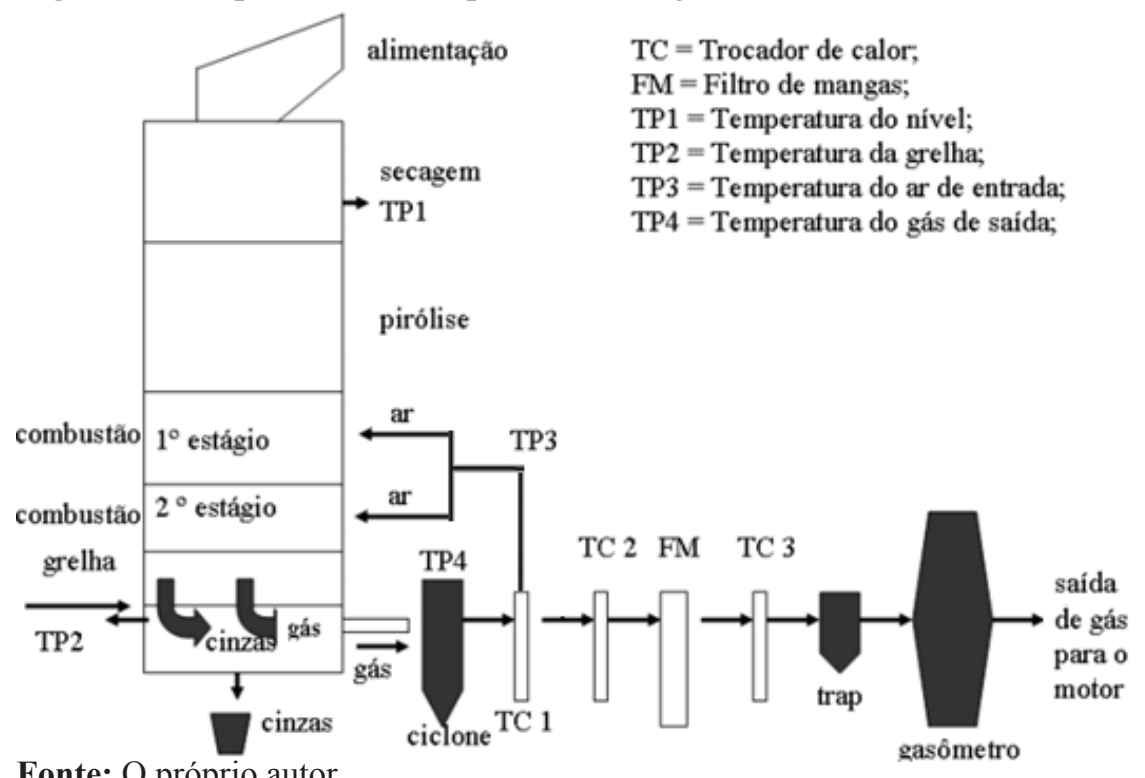


Para realizar o monitoramento das temperaturas foram instalados termopares tipo K. A localização dos termopares é apresentada na Figura 6.

AFigura 4 apresenta um esquema do gaseificador, suas divisões e funções de operação.

Figura 4 - Detalhe da planta do gaseificador com detalhamento dos componentes e das zonas específicas

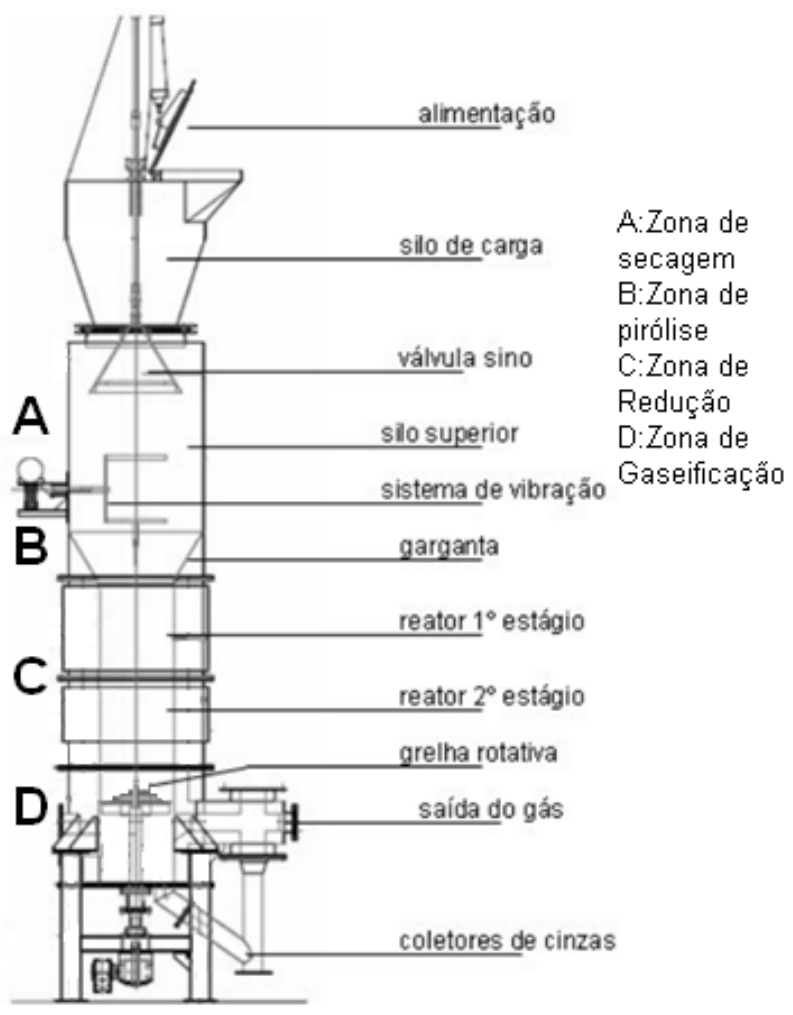

Fonte: Termoquip, 2011.

A zona de secagem, ou silo é um depósito interno que tem a função de dar ao gaseificador uma maior autonomia em sua operação, além de ir secando a biomassa que ali permanece. Existe acoplado à zona de secagem, um sistema de vibração temporizado cuja função é auxiliar o processo de descida da biomassa conforme a mesma vai sendo consumida nas zonas inferiores. O sistema de vibração é programado para funcionar durante 4 segundos a cada 4 minutos de modo a auxiliar a descida da biomassa para o gaseificador. Acima do silo está a área de carga, que é um estoque de combustível, a reposição desta biomassa é feita de forma manual, de acordo com o indicativo dado pelo TP1. A passagem da biomassa é feita através de uma válvula em forma de sino, cuja abertura é pneumática.

Na zona de pirólise, tem inicio a produção de gases, alcatrão e material particulado, terminando na zona de redução. Toda biomassa fica suspensa por uma grelha rotativa em forma de tronco de cone que fica logo abaixo da zona de redução.

$\mathrm{Na}$ zona de combustão, o diâmetro interno do gaseificador é reduzido, fazendo com que a velocidade dos gases aumente, facilitando a manutenção de temperaturas uniformes na seção transversal, o que por sua vez ocasiona o craqueamento térmico do alcatrão. O gás é liberado na zona de oxidação.

A quantidade de ar insuflada para dentro do gaseificador é regulada através de válvulas, uma para cada estágio de gaseificação e o volume de agente gaseificador insuflado é avaliado através do uso de placas de orifício, onde a diferença de pressão é medida em mmca.

O gaseificador tem $6,82 \mathrm{~m}$ de altura, $1000 \mathrm{~mm}$ de diâmetro externo e $550 \mathrm{~mm}$ de diâmetro interno. É fabricado com chapas de aço carbono e tem seu interior revestido com concreto refratário isolante HVL 24.

O sistema de fornecimento de ar é um soprador Siemens com rotação de 3405 RPM com vazão máxima com vazão máxima de $2,8 \mathrm{~m}^{3} / \mathrm{min}$. O Sistema de aquecimento de ar é composto de um trocador de calor, que fornece calor ao ar que é insuflado através do calor do gás produzido.

As cinzas são retiradas através da grelha rotativa, que pode ter sua rotação ajustada para, no máximo duas voltas por hora, em sentido horário ou antihorário. A grelha possui ranhuras e lacunas para raspar as cinzas e empurra-las ao reservatório.

Além do ciclone, o sistema de limpeza do gás é composto um filtro de mangas.

O filtro de mangas é composto de 4 mangas de poliéster teflonado com gramatura de $550 \mathrm{~g} / \mathrm{m}^{2}$ e possuem as seguintes dimensões: Ø 200 x $1500 \mathrm{~mm}$. 
Após o filtro de mangas, existe uma trap, cujo objetivo é favorecer a condensação da água presente no gás. Essa trap é uma estrutura de aço de $163 \mathrm{~mm}$ de diâmetro e $540 \mathrm{~mm}$ de altura que evita a passagem direta do gás através de uma chapa de aço onde a água presente no gás é condensada e recolhida. Existe também uma válvula para a remoção da água de dentro da trap. Após a passagem do gás pela trap, este vai para um gasômetro, onde sua pressão é regulada para ser encaminhado para o motor.

No gaseificador também está presente um sistema de eliminação do excesso de gás por queima no flare. Sua função não é exclusivamente eliminar o excesso, esse sistema também é utilizado para queimar o gás quando o mesmo não está sendo utilizado no motor, evitando sua liberação na atmosfera.

\section{Biomassa}

A biomassa utilizada foi madeira de eucalipto, proveniente de escoras utilizadas na construção civil. As escoras utilizadas são preferencialmente aquelas cujo diâmetro varia de 70 a 100 mm. As escoras são cortadas em pedaços de 80 a $100 \mathrm{~mm}$. As características da madeira de eucalipto estão relatadas na Tabela 2.

Tabela 2 - Composição elementar e imediata da madeira de eucalipto.

Tipo de Biomassa: Lenha de Eucalipto

\begin{tabular}{l|l|l}
\hline \multirow{4}{*}{$\begin{array}{l}\text { Composição } \\
\text { Elementar (\%) }\end{array}$} & $\mathrm{C}$ & 49,00 \\
\cline { 2 - 3 } & $\mathrm{H}$ & 5,87 \\
\cline { 2 - 3 } & $\mathrm{O}$ & 43,97 \\
\cline { 2 - 3 } & $\mathrm{S}$ & 0,30 \\
\cline { 2 - 3 } & Cinzas & 0,01 \\
\hline \multirow{2}{*}{ Composição } & Voláteis & 81,42 \\
\cline { 2 - 3 } Imediata (\%) & Cinzas & 0,79 \\
\hline PCS (MJ/kg) & Carbono fixo & 17,82 \\
\hline PCI (MJ/kg) & 19,42 & \\
\hline
\end{tabular}

Fonte: Jenkins, 1990
As dimensões das partículas de madeira tem grande influência na produção de alcatrão, por isso a madeira é cortada de modo a formar grandes partículas, o que resulta numa menor produção de alcatrão. Essa menor produção decorre do fato de partículas maiores fornecerem mais locais para que o alcatrão seja destruído e também da pirólise ocorrer mais lentamente em relação a partículas pequenas.

A umidade da madeira utilizada foi calculada segundo o método de secagem em estufa e foi de $15,9 \% \pm 2,2 \%$. (MARTINS, 1988).

\section{Grupo gerador}

Para compor um grupo gerador de 50 kVA (45 kW), é necessário um motor cuja relação torque $\mathrm{x}$ rotação seja obtida a 1800rpm, que é a rotação necessária para gerar na frequência da rede elétrica $(60 \mathrm{~Hz})$ com gerador de dois polos (AZENHOFER et al., 1971, p. 42). Para tal, foi necessário adaptar um motor ciclo Diesel, transformando-o em ciclo Otto, posto que os motores disponíveis no mercado, para ciclo Otto, apresentam potência máxima a rotações bem mais elevadas.

O sistema é regulado pela abertura e fechamento do corpo borboleta, instrumento este que permite o controle de entrada da mistura ar/combustível adequada, de acordo com a necessidade da carga aplicada ao motor. O Quadro 1 resume as principais características do motor.

Quadro 1 - Resumo das principais características técnicas do motor utilizado nos ensaios.

\begin{tabular}{|l|l|}
\hline \multicolumn{2}{|l|}{ Motor MWM D 229-4 } \\
\hline Aspiração & Natural \\
\hline Disposição/cilindro/válvulas & Linha/4/8 \\
\hline Cilindrada total & 3,92 Litros \\
\hline Diâmetro x Curso & $102 \times 120 \mathrm{~mm}$ \\
\hline Taxa de compressão & $11: 1$ \\
\hline Sistema de ignição & ER-BR \\
\hline Misturador ar/combustível & Mixer 50 \\
\hline
\end{tabular}

Fonte: o próprio autor 
Foi utilizado o gerador Kohlbach KCEL acoplado ao motor. Trata-se de um gerador trifásico síncrono "brushless", devido ao fato de que neste tipo de gerador o regulador se adéqua à velocidade do rotor.

\section{Coleta de amostras}

Para realizar a amostragem do alcatrão, foi preparado um frasco borbulhador com isopropanol. Este frasco foi conectado a linha de gás e então o gás produzido foi borbulhado em isopropanol para que os componentes do alcatrão fossem retidos no mesmo. Antes de o gás chegar ao borbulhador o mesmo passa por um filtro onde o material particulado é retido.
Após ser borbulhado o gás passa por um dispositivo que mede a vazão do mesmo.

Os compostos são extraídos do cartucho com acetonitrila e analisados por um cromatógrafo.

A amostragem foi realizada depois do filtro de mangas, para que seja avaliada a qualidade do gás que está indo para o motor.

Após 46 horas de funcionamento utilizando o gás produzido o motor foi aberto para que fossem avaliados os impactos gerados pelo uso do gás.

\section{Resultados e Discussão}

O gás produzido pelo gaseificador, após passar por todo o sistema teve a composição média mostrada na Tabela 5.

Tabela 5 - Composição média do gás produzido no gaseificador.

\begin{tabular}{c|c|c|c|c|c|c}
\hline Elemento & $\mathrm{H}_{2}$ & $\mathrm{O}_{2}$ & $\mathrm{~N}_{2}$ & $\mathrm{CO}$ & $\mathrm{CO}_{2}$ & $\mathrm{CH}_{4}$ \\
\hline$\%$ & 16,9 & $<0,1$ & 50,6 & 19,8 & 10,6 & 2,1 \\
\hline
\end{tabular}

Fonte: o próprio autor

$\mathrm{Na}$ amostra de gás que foi borbulhado poliaromáticos): nalftaleno, fluoreno, e em frasco contendo isopropanol, foram antraceno. A figura 5 mostra o cromatograma encontrados os seguintes HPAs (hidrocarbonetos obtido da amostra borbulhada.

Figura 5 - Cromatograma obtido da amostra de alcatrão borbulhada em frasco com isopropanol.

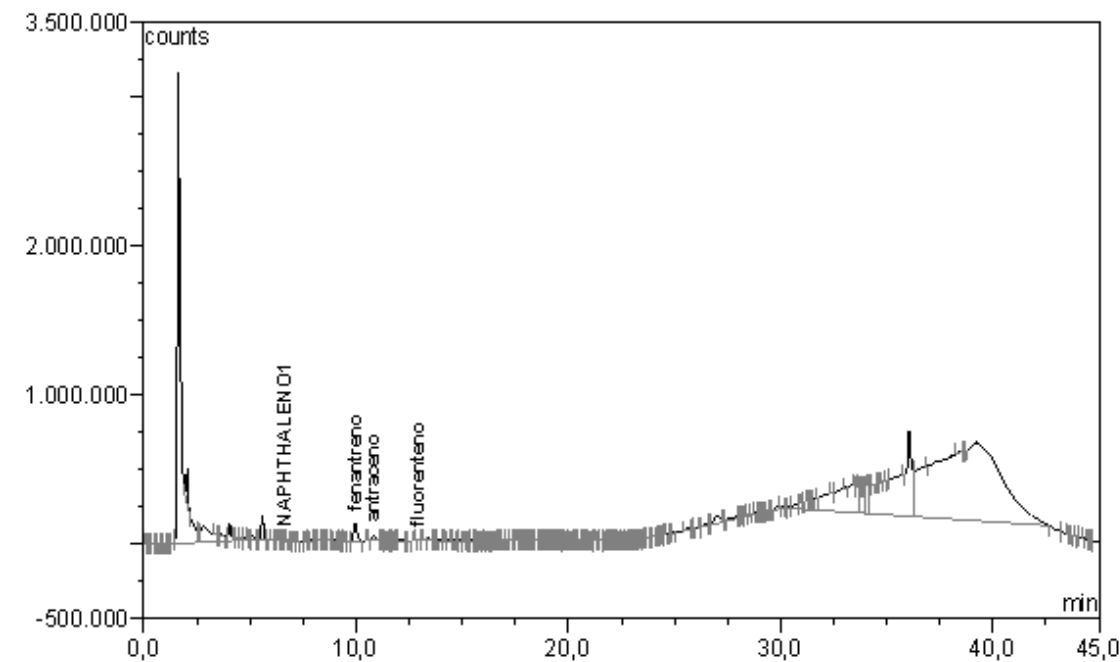

Fonte: o próprio autor. 
Tais compostos, originados da queima incompleta de materiais carbonáceos, são também encontrados nas emissões de motores veiculares à gasolina $\mathrm{e}$ diesel/biodiesel.

A concentração dos compostos presentes na amostra em que o gás foi borbulhado foi de $1,30 \mu \mathrm{g} / \mathrm{Nm}^{3}$.
Tal concentração é abaixo da faixa de concentração aceitável para motores de combustão interna, que é de $50-100 \mathrm{mg} / \mathrm{Nm}^{3}$ de alcatrão.

$\mathrm{Na}$ amostragem dos gases de escape, foram encontrados os mesmos HPAs da amostra borbulhada e mais acenaftaleno e acenafteno. A figura 6 mostra o cromatograma obtido da amostra dos gases de escape.

Figura 6 - Cromatograma obtido da amostra dos gases de escape

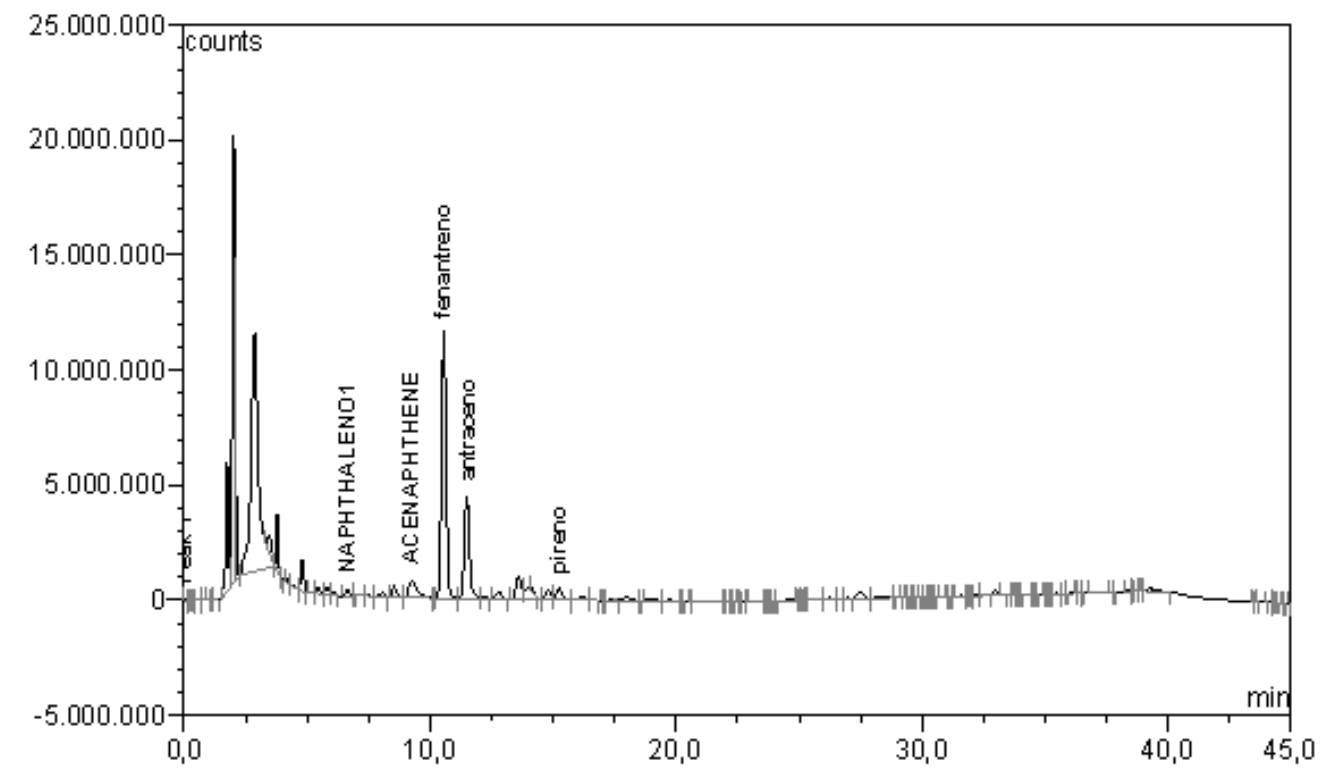

Fonte: o próprio autor.

A concentração dos compostos presentes na amostra dos gases de escape foi de $96,77 \mu \mathrm{g} / \mathrm{Nm}^{3}$.

Nos gases de escape a concentração de HPAs encontrada foi maior do que a concentração encontrada no gás borbulhado.

Tal fato sugere três justificativas: a primeira, o método utilizado para reter os HPAs em isopropanol não foi satisfatório; a segunda, houve combustão incompleta do gás produzido no motor, ocasionando um aumento na concentração dos HPAs e a terceira, e mais provável, os HPAs detectados são resultados da queima do óleo do motor.

No gás que é enviado ao motor, a quantidade de material particulado foi de $0,16 \mathrm{mg} / \mathrm{Nm}^{3}$. O limite aceitável de material particulado para motores de combustão interna varia entre 10 e $50 \mathrm{mg} / \mathrm{Nm}^{3}$, portanto o conjunto do gaseificador é capaz de produzir um gás com teor de material particulado aceitável. (MILNE; EVANS, 1998).

A abertura do motor ocorreu após 46 horas de funcionamento. Com a abertura, pôde-se constatar que apesar do FA obtido ser baixo e teoricamente produzir maior quantidade de alcatrão, o motor estava em perfeitas condições, não sofrendo nenhum tipo de avaria devido ao alcatrão e material particulado proveniente do gás, isso se deve a temperatura na qual o gaseificador estava sendo operado.

\section{Conclusão}

Após 46 horas de funcionamento com syngas o motor se manteve em perfeitas condições de 
funcionamento, não apresentando contaminação por alcatrão ou material particulado. O teor de HPA's no gás enviado ao motor foi de $1,30 \mu \mathrm{g} / \mathrm{Nm}^{3}$ e o teor de material particulado foi de $0,16 \mathrm{mg} / \mathrm{Nm}^{3}$, em ambos casos, valores abaixo dos limites aceitáveis para o funcionamento do motor.

\section{Referências}

AZENHOFER, K.; HEIM, T.; SHULTHEISS, A.; WEBER, W. Eletrotécnica para escolas profissionais. São Paulo: Mestre Jou, 1971. 130 p.

BUI, T.; LOOF, R.; BHATTACHARYA, S. C. Multistage reactor for thermal gasification of wood. Energy, v. 19, n. 4, p. 397-404, 1994.

CIFERNO, J. P.; MARANO, J. J. Benchmarking biomass gasification technologies for fuels, chemicals and hydrogen production. U.S.: Department of energy, national energy technology laboratory. 2002.

DEVI, L.; PTASINSKI, K. J.; JANSSEN, F. J. J. G. A review of the primary measures for tar elimination in biomass gasification processes. Biomass and Bioenergy, v. 24, n. 2, p. 125-140, 2003.

FRANCO, C.; PINTO, F.; GULYUTLU, I.; CABRITA, I. The study of reactions influencing the biomass steam gasification process. Fuel, v. 82, n. 7, p. 835-842, 2003.

FRIENDS OF THE EARTH- FOE. Briefing pyrolysis and gasification. 2009.

JENKINS, B. M. Fuel Properties for Biomass Materials. In: INTERNATIONAL SYMPOSIUM ON APPLICATION AND MANAGEMENT OF ENERGY IN AGRICULTURE: The role of biomass fuels. Delhi, 1990.

NEEFT, J. P. A.; KNOEF, H. A. M.; ONAJI, P. Behaviour of tar in biomass gasification systems. Tar related problems and their solutions. The Netherlands: Novem Report, 1999.

MARTINS, V. A. Secagem de madeira serrada. Brasília: IBDF, 1988.

MCKENDRY, P. Energy production from biomass (part 2): conversion technologies. Bioresource Technology, v. 83 , n. 1, p. 47-54, 2002a.
. Energy production from biomass (part 3): gasification technologies. Bioresource Technology, v. 83, n. 1, p. 55-63, 2002b.

MILNE, T. A.; EVANS, R. J. Biomass gasification "tars": their nature, formation and conversion. Golden: NREL, 1998.

QUAAK, P.; KNOEF, H.; STASSEN, H. World bank technical paper n. 422, Energy Series. Washington: World band, 1999.

SÁNCHEZ, C. G. Tecnologia da gaseificação de biomassa. Campinas: Átomo, 2009.

TERMOQUIP. Energia alternativa Ltda. Campinas, 2009. 
